\title{
Impact of Electronic Health Record Clinical Decision Support on Diabetes Care: A Randomized Trial
}

Patrick J. O'Connor, MD, MPH'

JoAnn M. Sperl-Hillen, $M D^{1}$

William A. Rush, $P b D^{1}$

Paul E. Jobnson, $P b D^{2}$

Gerald H. Amundson, BS

Stephen E. Asche, $M A^{1}$

Heidi L. Ekstrom, $M A^{1}$

Todd P. Gilmer, $P b D^{3}$

'HealthPartners Research Foundation and HealthPartners Medical Group, Minneapolis, Minnesota

${ }^{2}$ Carlson School of Management, University of Minnesota, Minneapolis, Minnesota

${ }^{3}$ University of California at San Diego, San Diego, California
Conflicts of interest: authors report none.

\section{CORRESPONDING AUTHOR}

Patrick J. O'Connor, MD, MPH

HealthPartners Research

PO Box 1524

Minneapolis, MN 55440-1524

Patrick.j.oconnor@healthpartners.com

\begin{abstract}
PURPOSE We wanted to assess the impact of an electronic health record-based diabetes clinical decision support system on control of hemoglobin $A_{1 c}$ (glycated hemoglobin), blood pressure, and low-density lipoprotein (LDL) cholesterol levels in adults with diabetes.
\end{abstract}

METHODS We conducted a clinic-randomized trial conducted from October 2006 to May 2007 in Minnesota. Included were 11 clinics with 41 consenting primary care physicians and the physicians' 2,556 patients with diabetes. Patients were randomized either to receive or not to receive an electronic health record (EHR)based clinical decision support system designed to improve care for those patients whose hemoglobin $A_{1 c}$, blood pressure, or LDL cholesterol levels were higher than goal at any office visit. Analysis used general and generalized linear mixed models with repeated time measurements to accommodate the nested data structure.

RESULTS The intervention group physicians used the EHR-based decision support system at $62.6 \%$ of all office visits made by adults with diabetes. The intervention group diabetes patients had significantly better hemoglobin $A_{1 c}$ (intervention effect $-0.26 \%$; $95 \%$ confidence interval, $-0.06 \%$ to $-0.47 \% ; P=.01)$, and better maintenance of systolic blood pressure control $(80.2 \%$ vs $75.1 \%, P=.03)$ and borderline better maintenance of diastolic blood pressure control $(85.6 \%$ vs $81.7 \%, P=.07)$, but not improved low-density lipoprotein cholesterol levels $(P=.62)$ than patients of physicians randomized to the control arm of the study. Among intervention group physicians, 94\% were satisfied or very satisfied with the intervention, and moderate use of the support system persisted for more than 1 year after feedback and incentives to encourage its use were discontinued.

CONCLUSIONS EHR-based diabetes clinical decision support significantly improved glucose control and some aspects of blood pressure control in adults with type 2 diabetes.

Ann Fam Med 2011;9:12-21. doi:10.1370/afm.1196.

\section{INTRODUCTION}

$\mathrm{D}$ espite recent improvement trends in the United States, in 2008 less than $20 \%$ of patients with diabetes concurrently reach evidence-based goals for hemoglobin $\mathrm{A}_{1 \mathrm{c}}$ (glycated hemoglobin), systolic and diastolic blood pressure, and low-density lipoprotein (LDL) cholesterol levels. ${ }^{1,2}$ Care is unsatisfactory in both subspecialty and primary care settings, but because more than $80 \%$ of diabetes care is delivered by primary care physicians, effective strategies to improve diabetes care in primary care settings are urgently needed.

Among the major barriers to better diabetes care is lack of timely intensification of pharmacotherapy in patients who have not achieved recommended clinical goals. Many factors contribute to this problem, including competing demands at the time of the visit ${ }^{3}$ and medication 
nonadherence. ${ }^{4}$ Rates of treatment intensification when patients are not at goal, however, hover around $70 \%$ to $80 \%,{ }^{5}$ and several studies have linked higher rates of treatment intensification by a primary care physician to better rates of hypertension, lipid, or glucose control in that primary care physician's patients. ${ }^{6}$

In theory, treatment intensification and control of hemoglobin $\mathrm{A}_{1 \mathrm{c}}$, blood pressure, and lipid levels in patients with diabetes mellitus could be improved by providing patient-specific and drug-specific clinical decision support at the time of a clinical encounter. Electronic health records (EHRs) can be programmed to include sophisticated clinical algorithms that take advantage of current and past clinical information to provide detailed clinical recommendations at the time of a clinical encounter. ${ }^{7-9}$ Prior efforts have typically improved processes of care (such as rate of hemoglobin $\mathrm{A}_{1 \mathrm{c}}$ or LDL cholesterol testing or eye examinations) but failed to improve key intermediate outcomes of care, such as control of hemoglobin $\mathrm{A}_{1 \mathrm{c}}$, blood pressure, or LDL cholesterol levels. ${ }^{10-16}$ It is especially important to improve hemoglobin $\mathrm{A}_{1 \mathrm{c}}$, blood pressure, and LDL cholesterol levels, because appropriate control of these risk factors can substantially influence the rate of major microvascular or macrovascular complications of diabetes. ${ }^{17-21}$

Beyond diabetes care, many studies document the failure of EHR-based clinical decision support to improve key intermediate clinical outcomes in patients with hypertension, congestive heart failure care, asthma, and other conditions. ${ }^{22-25}$ A careful reading of these failed studies, including several of our own, identified several possible reasons why EHR-based clinical decision support failed to improve intermediate outcomes of chronic disease care. First, most clinical decision support was limited to general prompts and reminders and did not include more detailed drugspecific advice. Second, introduction of EHR-based clinical decision support was usually not accompanied by changes in staff responsibilities and clinic workflow to enhance the impact of the clinical decision support on care. Third, rather than being used for visit planning, clinical decision support displays were usually provided late in the encounter and were often skipped over or not viewed by physicians. Finally, physicians typically received no tangible compensation or reward for the extra time and effort needed to adopt new and unfamiliar clinical routines.

Based on these observations, we developed, pilot tested, and refined a novel patient-customized EHRbased clinical decision support system for type 2 diabetes care designed to overcome obstacles to use observed in earlier studies. Here we report a clinicrandomized trial that assessed the impact of this EHRbased clinical decision support system on intermediate outcomes of diabetes care, including hemoglobin $\mathrm{A}_{1 \mathrm{c},}$ blood pressure, and LDL cholesterol control.

\section{METHODS}

The study was reviewed in advance, approved, and monitored on an ongoing basis by the HealthPartners Institutional Review Board, project \#03-083, and by an independent data safety and monitoring board.

\section{Design Overview}

This group-randomized trial tested the hypothesis that an EHR-based clinical decision support system would improve hemoglobin $\mathrm{A}_{1 \mathrm{c}}$, blood pressure, and lipid control in adults with type 2 diabetes receiving care from primary care physicians.

\section{Setting and Participants}

The study was conducted at HealthPartners Medical Group (HPMG), a large medical group in Minnesota that provided care to approximately 9,000 adults with diabetes in 2007 . Most diabetes care was provided by primary care physicians; $10 \%$ of type 2 patients each year see an endocrinologist, most for 1 visit.

Primary care physicians were eligible for the study if they practiced in a study clinic, provided care to at least 10 adults with type 2 diabetes, and provided written informed consent to participate. Patients were classified as having diabetes if they had 2 or more outpatient diabetes International Classification of Diseases, Ninth Revision (ICD-9) codes (250.xx) or used 1 or more diabetes-specific medications in the 1 -year period before randomization. ${ }^{26}$ This diabetes identification method has estimated sensitivity of 0.91 and positive predictive value of $0.94 .^{26}$

\section{Randomization and Interventions}

Eleven HPMG clinics that used EHRs for 2 or more years were included in this study. Pairs of clinics having a similar proportion of patients at a composite diabetes care goal were placed into strata. Within each stratum a clinic was randomly assigned to either the intervention or control arm.

The EHR-based diabetes clinical decision support system (referred to as Diabetes Wizard) was provided to physicians at the 6 intervention clinics. Nursing staff and physicians participated in a 1-hour training session during which they were instructed that the Diabetes Wizard was not meant to override or supersede clinical judgment, and that its use was limited to type 2 diabetes patients aged 18 to 75 years. Adults aged 75 years and older and those with a Charlson comorbidity scores of 3 or more (indicating high short-term risk of mortality) were excluded from the study because of 
legitimate debate about appropriate clinical goals in such patients. ${ }^{27-29}$

Diabetes Wizard implementation included the following changes in clinic workflow at intervention clinics. (1) The rooming nurse enters blood pressure readings into EHR as usual. (2) If the patient has diabetes, the rooming nurse opens the Diabetes Wizard in the EHR with a single click on the navigation bar, prints the EHR-generated Diabetes Wizard form (Figure 1), and closes the form in the EHR. (3) The rooming nurse places the printed form on top of the visit summary sheet on the examination room door. (4) The physician reviews the available diabetes treatment options printed on the form just before entering the room and proceeds with the visit. (5) After the visit but before closing the encounter, the physician opens the Diabetes Wizard form in the EHR visit navigator and completes the brief visit resolution form.

Diabetes Wizard recommendations are based on detailed clinical algorithms constructed by the research team (J.S.H., P.J.O.) consistent with evidence-based

\begin{tabular}{|c|c|c|}
\hline \multicolumn{3}{|l|}{ Glucose $/ A_{1 c}$} \\
\hline \multicolumn{3}{|c|}{$* * * * *$ NOT AT GOAL***** } \\
\hline & Date & Goal \\
\hline$A_{1 c}: 8.4$ & $9 / 15 / 2007$ & $<7 \%$ \\
\hline CR: 1.3 & $9 / 15 / 2007$ & \\
\hline \multicolumn{3}{|c|}{ CHF Dx: Not Identified } \\
\hline \multicolumn{3}{|c|}{ Current Glucose Meds: } \\
\hline \multicolumn{3}{|c|}{ Glipizide 10 mg qd } \\
\hline \multicolumn{3}{|c|}{ ***TREATMENTS TO CONSIDER*** } \\
\hline \multicolumn{3}{|c|}{$\begin{array}{l}\text { - The treatment recommendations only apply to Type } 2 \\
\text { Diabetes! }\end{array}$} \\
\hline \multicolumn{3}{|c|}{$\begin{array}{l}\text { - Start metformin } 500 \mathrm{mg} \text { po qd or bid. Increase dose by } \\
500 \mathrm{mg} \text { every } 1-2 \text { weeks based on SMBGs to a max of } \\
1000 \mathrm{mg} \text { po bid or to } A_{1 c} \text { goal. }\end{array}$} \\
\hline \multicolumn{3}{|l|}{ OR } \\
\hline \multicolumn{3}{|c|}{$\begin{array}{l}\text { - Start a thiazolidinedione (e.g. pioglitazone } 15 \mathrm{mg} \text { po qd). } \\
\text { Increase dose every } 6-8 \text { weeks to maximum } 45 \mathrm{mg} \text { qd or } \\
\text { to } A_{1 c} \text { goal. }\end{array}$} \\
\hline \multicolumn{3}{|c|}{$* * * *$ COMMENTS $\&$ ALERTS $* * * * *$} \\
\hline \multicolumn{3}{|c|}{ Consider monthly visits until better glycemic control is achieved! } \\
\hline \multicolumn{3}{|c|}{ Was Glucose Treatment Modified? } \\
\hline $\begin{array}{l}\text { Yes...Any } \\
\text { of above }\end{array}$ & $\begin{array}{l}\text { Yes...Other } \\
\text { than Above }\end{array}$ & No \\
\hline \multicolumn{3}{|c|}{$\begin{array}{l}A_{1 C}=\text { glycated hemoglobin; } \text { bid = twice a day; } C H F=\text { congestive heart fail- } \\
\text { ure; } C R=\text { serum creatinine; } D x=\text { diagnosis; } p o=\text { orally; } q d=\text { every day; } \\
\text { SMBG = self-monitored blood glucose. }\end{array}$} \\
\hline \multicolumn{3}{|c|}{$\begin{array}{l}\text { Note: Diabetes Wizard screen shot with fictional clinical data for a hypothetical } \\
68 \text {-year-old man on the fictional visit date of September } 15,2007 \text {. The ques- } \\
\text { tions at the bottom are components of the Visit Resolution Form and could be } \\
\text { excluded from subsequent versions of Diabetes Wizard. }\end{array}$} \\
\hline
\end{tabular}

diabetes guidelines from the Institute for Clinical Systems Improvement and from other evidence-based sources. ${ }^{30-31}$ Diabetes Wizard provides recommendations in the following categories: (1) suggests specific changes in medications for patients not at individualized hemoglobin $\mathrm{A}_{1 \mathrm{c}}$, blood pressure, or lipid goals; (2) suggests changes in treatment for patients with contraindications to existing treatments (eg, metformin use in renal insufficiency or congestive heart failure), or being treated with potentially risky drug combinations (eg, concomitant $\beta$-blocker and nondihydropyridine calcium channel blocker); (3) suggests obtaining overdue laboratory tests, such as for potassium, serum creatinine, creatinine kinase, or liver function tests; and (4) suggests short follow-up intervals, such as monthly visits, for patients not at goal, because more frequent visits are associated with better chronic disease outcomes in many clinical trials.

After each office visit at which the Diabetes Wizard was deployed, the physician was asked to complete a brief (15 seconds per clinical domain) visit resolution form to indicate whether treatment was intensified at the time of the visit. The fastest way to complete the visit resolution form was to intensify pharmacotherapy for patients not at goal. Lifestyle advice was also considered an intervention. If no intervention occurred, physicians were asked to specify why not.

During the 6-month intervention period, physicians and clinics received monthly summaries and feedback to encourage high rates of Diabetes Wizard use and visit resolution form completion. Compensation was provided to encourage Diabetes Wizard use. Nursing staff at each intervention clinic collectively received $\$ 500$ compensation for training time and increased workload during the 6 -month intervention period. Consenting intervention group physicians were compensated $\$ 800$ at the start of the intervention and another $\$ 800$ after 6 months if they completed visit resolution forms for at least $70 \%$ of all diabetes encounters. After 6 months both compensation and feedback stopped, but intervention physicians were encouraged to continue to use the Diabetes Wizard, and use was tracked electronically for 15 more months.

\section{Outcomes and Follow-up}

The principal dependent variable was the preintervention to postintervention change in hemoglobin $\mathrm{A}_{1 \mathrm{c} \text {, }}$ blood pressure, and LDL cholesterol levels. The baseline test value for hemoglobin $\mathrm{A}_{1 \mathrm{c}}$ and LDL cholesterol was the first test during the intervention (or last preintervention test if there was no intervention value). For systolic and diastolic blood pressures, the baseline was the last preintervention value. For all tests, postintervention status was based on the last postintervention 
test value. All hemoglobin $A_{1 c}$ assays were done at a single accredited clinical chemistry laboratory using a standard liquid chromatographic assay with a normal range of $4.5 \%$ to $6.1 \%$ and a coefficient of variation of $0.58 \%$ at a hemoglobin $\mathrm{A}_{1 \mathrm{c}}$ value of $8.8 \% .{ }^{32} \mathrm{LDL}$ cholesterol values were calculated based on standard assays of total cholesterol, high-density lipoprotein (HDL) cholesterol, and 12-hour fasting triglycerides only when the triglyceride level was less than $400 \mathrm{mg} /$ $\mathrm{dL} .{ }^{33}$ No changes in these laboratory assay methods occurred during the study period. Blood pressure was measured according to office routine by nursing staff or physicians, who were periodically trained in proper blood pressure measurement technique. The blood pressure value in the primary EHR vital signs slot was selected for analysis.

\section{Statistical Analysis}

The independent variable of major interest was an indicator variable for the study arm. The interaction of study arm with time assessed the differential impact of the intervention across study arms on prespecified outcomes of hemoglobin $\mathrm{A}_{1 \mathrm{c}}$, systolic and diastolic blood pressure, and LDL cholesterol values. Because the trial was randomized at the clinic level, imbalance in patient characteristics was likely. Patient-level independent variables included age, sex, and validated indicator variables for coronary heart disease and congestive heart failure. ${ }^{34}$

This nested cohort pretest-posttest control group design accommodated clustering of occasion of measurement (baseline and postintervention) within patients who were nested within physicians who were nested within clinics. General and generalized linear mixed models with a repeated time measurement (baseline and postintervention) were used to analyze continuous (eg, laboratory values) and binary (eg, proportion of patients with a hemoglobin $\mathrm{A}_{1 \mathrm{c}}$ test) outcomes using SAS Proc Mixed and Proc Glimmix (SAS Institute, Cary, North Carolina). These models included a term for study arm, time (baseline or postintervention), a time $\times$ study arm interaction term, and random intercepts to account for multiple levels of nesting. The time $\times$ study arm interaction term tested the effect of the intervention arm over time relative to the effect of the control arm over time. The analyses on test values were also conducted predicting postintervention values from study arm, preintervention test value, and patient covariates. Because of the similarity in results from these two approaches, we report the findings from the time $\times$ study arm approach.

Denominators for the analysis of test rates, encounter rates, and numbers of tests and encounters included the full set of eligible patients linked to study-consent- ing physicians. Patients with diabetes encounters in the postintervention period and not at goal at baseline (eg, hemoglobin $A_{1 c} \geq 7 \%$, blood pressure $\geq 130 / 80 \mathrm{~mm} \mathrm{Hg}$, LDL cholesterol $\geq 100 \mathrm{mg} / \mathrm{dL}$ [ $\geq 70 \mathrm{mg} / \mathrm{dL}$ for coronary heart disease]) comprised the denominator for analysis examining change in hemoglobin $\mathrm{A}_{1 \mathrm{c}}$ levels. Patients with diabetes encounters and at goal at baseline (eg, hemoglobin $\mathrm{A}_{1 \mathrm{c}}<7 \%$, systolic blood pressure $<130$ $\mathrm{mm} \mathrm{Hg}$, diastolic blood pressure $<80 \mathrm{~mm} \mathrm{Hg}$, LDL cholesterol $<100 \mathrm{mg} / \mathrm{dL}[<70 \mathrm{mg} / \mathrm{dL}$ for coronary heart disease]) comprised the denominator for analysis examining maintenance of clinical goals at the last follow-up measurement. For analyses of laboratory values, patients missing a value at baseline were not included in the analysis because we were unable to determine whether such cases were at goal at baseline. Patients without a postintervention value, however, were included through restricted maximum likelihood estimation, which uses information from patients with partially missing data. ${ }^{35}$ A priori sample size calculations assumed an analytic sample of 500 diabetes patients per study arm, based on 20 physicians with 25 diabetes patients not at goal on hemoglobin $\mathrm{A}_{1 \mathrm{c}}$ measurements. Effective patient sample size was estimated as $n=291$ per arm because of clustering of patients within physicians (estimated intraclass correlation coefficient $=0.03$ ). This study was designed with $80 \%$ power to detect a difference of $0.3 \%$ in hemoglobin $\mathrm{A}_{1 \mathrm{c}}$ levels between study arms, with a 2 -tailed $\alpha=.05$; $\alpha$ levels were not adjusted for testing 3 principal dependent variables.

\section{RESULTS}

Of the 11 clinics, 6 were randomly allocated to the study arm, and 5 to the usual care arm. From these clinics 40 physicians enrolled in the study, 20 in each study arm, with 2,556 eligible patients, 1,194 in the intervention arm, and 1,362 in the control arm. The allocation of clinics, physicians, and patients to study arm is shown in Figure 2.

Attributes of study participants are displayed in Table 1. At baseline, 47.8\% of diabetes patients had hemoglobin $\mathrm{A}_{1 \mathrm{c}}$ levels of $<7 \%, 59.1 \%$ had systolic blood pressures of $<130 \mathrm{~mm} \mathrm{Hg}, 65.6 \%$ had diastolic blood pressures of $<80 \mathrm{~mm} \mathrm{Hg}$, and $59.9 \%$ had LDL cholesterol $<100 \mathrm{mg} / \mathrm{dL}$. The range of diabetes patients per study-enrolled physician was 10 to 100 with a mean of 49.7 ( $\mathrm{SD}=25.0)$. Randomization at the clinic level resulted in an intervention arm with a higher proportion of male and white patients, and with higher baseline diastolic blood pressure and LDL cholesterol values than patients in the control arm. Intervention arm clinics had a higher proportion of family practice physicians than control arm clinics. 
Figure 2. Diagram illustrating randomization and disposition of clinics, primary care physicians, and diabetes patients.

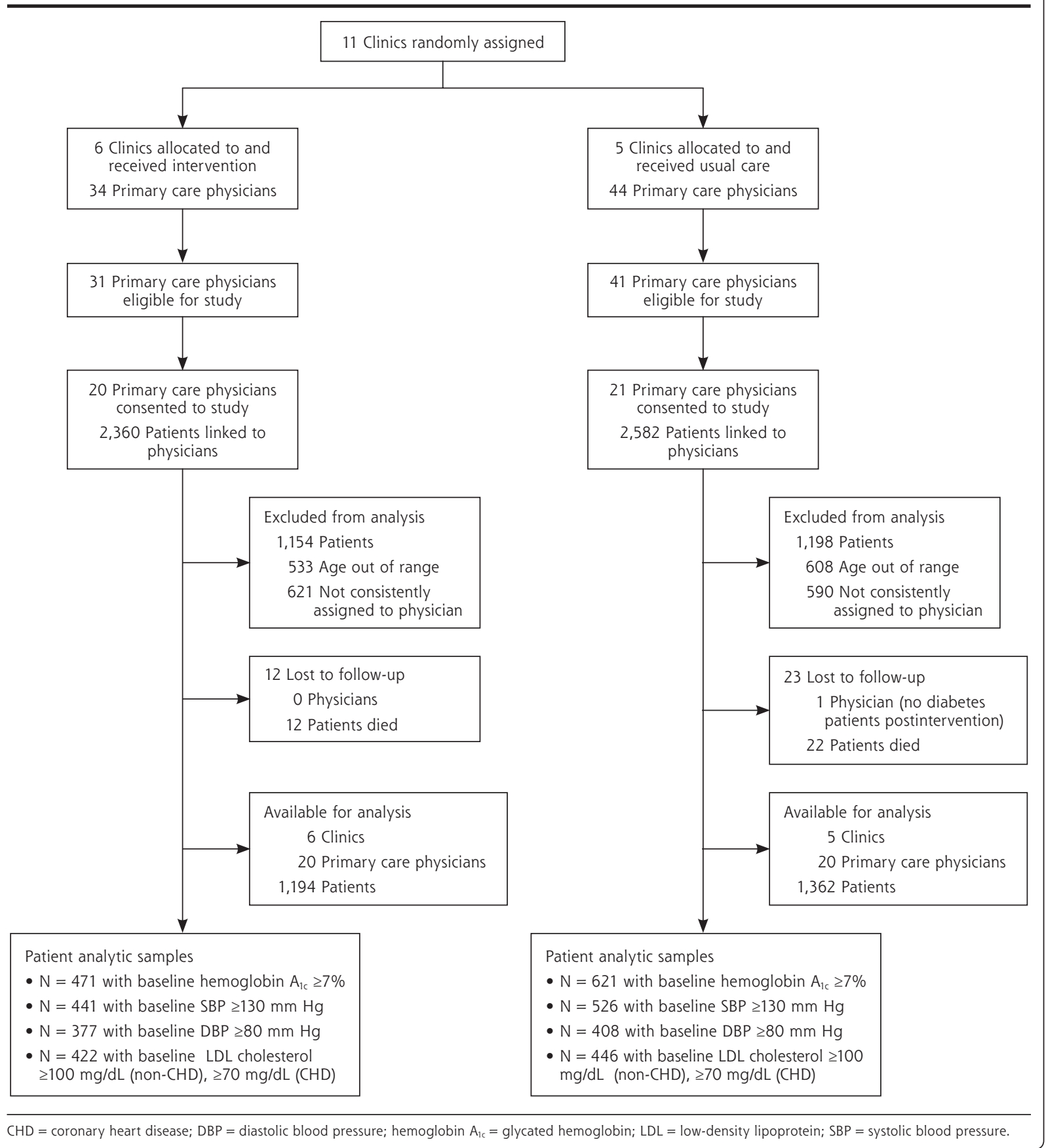

In 4-level random intercept models (measurement occasion nested within patient, physician, and clinic), intraclass correlations (ICCs) at the clinic level were small, with values of ICC $\leq 0.0002$ for hemoglobin $\mathrm{A}_{\mathrm{Ic}}$, systolic and diastolic blood pressures, and LDL cholesterol. Because of the low ICCs at the clinic level, 3-level models are presented by dropping the random intercept term for clinic.
Table 2 shows relatively high baseline and followup blood pressure and LDL cholesterol test rates, and little intervention effect on these measures during the study period. Proportion of patients with a hemoglobin $A_{1 c}$ test increased more in the intervention than control group $(P=.045)$, but the mean number of hemoglobin $\mathrm{A}_{\mathrm{cc}}(P=.09)$ and LDL cholesterol tests $(P=.09)$ per patient was not affected by the intervention. 
Table 3 shows that hemoglobin $\mathrm{A}_{1 \mathrm{c}}$ levels, systolic and diastolic blood pressures, and LDL cholesterol values each significantly improved with time in both study arms (all $P<.001)$. Intervention arm patients had a significantly greater $(-0.26 \%)$ improvement in hemoglobin $A_{1 c}$ levels than control arm patients (95\% confidence interval $[\mathrm{CI}],-0.06 \%$ to $-0.47 \%$; time $\times$ condition $P=.01$ ). Although intervention and control arm patients had similar decreases in systolic blood pressures, intervention arm patients with controlled systolic blood pressure at

\section{Table 1. Characteristics of Study Physicians and Diabetes Patients Linked to Those Study Physicians at Intervention and Control Clinics}

\begin{tabular}{|c|c|c|c|}
\hline Variable & Intervention Clinic & Control Clinic & $P$ Value $^{\mathrm{a}}$ \\
\hline \multicolumn{4}{|l|}{ Patients } \\
\hline Total No. & 1,194 & 1,362 & \\
\hline Mean age (SD), y & $57.0(10.7)$ & $57.5(10.1)$ & .23 \\
\hline Female, \% & 46.7 & 54.5 & $<.001$ \\
\hline White race, \% & 82.8 & 70.6 & $<.001$ \\
\hline Coronary heart disease preintervention, $\%$ & 12.1 & 12.6 & .75 \\
\hline Congestive heart failure preintervention, \% & 2.9 & 3.6 & .35 \\
\hline Preintervention first glycated $A_{1 c}$ mean (SD) [median], \% & $7.4(1.68)[7.0]$ & $7.4(1.67)[7.0]$ & .47 \\
\hline Preintervention first systolic blood pressure, mean (SD) [median], mm Hg & $127.3(17.4)[126]$ & $126.8(17.1)[125]$ & .40 \\
\hline Preintervention first diastolic blood pressure, mean (SD) [median], mm Hg & 74.5 (10.9) [74] & $73.5(10.5)[74]$ & .023 \\
\hline Preintervention first LDL cholesterol value, mean (SD) [median], mg/dL & $99.4(34.5)[94]$ & $95.9(33.8)[90]$ & .019 \\
\hline \multicolumn{4}{|l|}{ Primary care physicians } \\
\hline Total No. & 20 & 20 & \\
\hline Age, mean (SD), y & $49.2(9.9)$ & $50.2(7.3)$ & .71 \\
\hline Family physician,\% & 80.0 & 45.0 & .02 \\
\hline Female physician, \% & 55.0 & 50.0 & .75 \\
\hline Diabetes patients per physician, mean (SD), No. & $43.7(17.3)$ & $55.8(30.2)$ & .13 \\
\hline
\end{tabular}

\section{Table 2. Rates and Counts of Diabetes Encounters, Glycated Hemoglobin Tests, Low-Density Lipoprotein Cholesterol Tests, and Blood Pressure Measures, Comparing Intervention and Control Clinics in the Preintervention and Postintervention Periods}

\begin{tabular}{|c|c|c|c|c|c|c|c|c|}
\hline \multirow[b]{2}{*}{ Variable } & \multicolumn{3}{|c|}{ Intervention Clinic } & \multicolumn{3}{|c|}{ Control Clinic } & \multirow[b]{2}{*}{$\begin{array}{c}\text { Intervention } \\
\text { Effect }^{\mathrm{a}}\end{array}$} & \multirow[b]{2}{*}{$\begin{array}{c}P \\
\text { Value }^{b}\end{array}$} \\
\hline & $\begin{array}{c}\text { Pre- } \\
\text { intervention } \\
12 \mathrm{mo}\end{array}$ & $\begin{array}{c}\text { Post- } \\
\text { intervention } \\
12 \text { mo }\end{array}$ & Change & $\begin{array}{l}\text { Pre- } \\
\text { intervention } \\
12 \mathrm{mo}\end{array}$ & $\begin{array}{c}\text { Post- } \\
\text { intervention } \\
12 \mathrm{mo}\end{array}$ & Change & & \\
\hline \multicolumn{9}{|c|}{ Patients with 1 or more encounters or tests, proportion (95\% Cl) } \\
\hline $\begin{array}{l}\text { Diabetes } \\
\text { encounters }\end{array}$ & $\begin{array}{c}.850 \\
(.820-.876)\end{array}$ & $\begin{array}{c}.949 \\
(.932-.962)\end{array}$ & $.099 \mathrm{c}$ & $\begin{array}{c}.875 \\
(.849-.897)\end{array}$ & $\begin{array}{c}.956 \\
(.941-.967)\end{array}$ & $.081^{\mathrm{c}}$ & .018 & .78 \\
\hline $\begin{array}{l}\text { Hemoglobin } \\
A_{1 c} \text { tests }\end{array}$ & $\begin{array}{c}.829 \\
(.788-.864)\end{array}$ & $\begin{array}{c}.940 \\
(.919-.956)\end{array}$ & $.112^{c}$ & $\begin{array}{c}.858 \\
(.822-.888)\end{array}$ & $\begin{array}{c}.929 \\
(.906-.947)\end{array}$ & $.071^{c}$ & .041 & .045 \\
\hline $\begin{array}{l}\text { Blood pressure } \\
\text { measurements }\end{array}$ & $\begin{array}{c}.986 \\
(.977-.991)\end{array}$ & $\begin{array}{c}.988 \\
(.980-.993)\end{array}$ & .003 & $\begin{array}{c}.986 \\
(.978-.991)\end{array}$ & $\begin{array}{c}.981 \\
(.971-.987)\end{array}$ & -.005 & .008 & .28 \\
\hline $\begin{array}{l}\text { LDL cholesterol } \\
\text { tests }\end{array}$ & $\begin{array}{c}.819 \\
(.779-.854)\end{array}$ & $\begin{array}{c}.871 \\
(.838-.899)\end{array}$ & $.052^{\mathrm{d}}$ & $\begin{array}{c}.846 \\
(.809-.876)\end{array}$ & $\begin{array}{c}.865 \\
(.831-.892)\end{array}$ & .019 & .033 & .14 \\
\hline \multicolumn{9}{|c|}{ Encounters or tests done per patient, mean $(95 \% \mathrm{Cl})$, No. } \\
\hline $\begin{array}{l}\text { Diabetes } \\
\text { encounters }\end{array}$ & $\begin{array}{c}3.9 \\
(3.6-4.4)\end{array}$ & $\begin{array}{c}4.5 \\
(4.1-4.9)\end{array}$ & $0.49^{d}$ & $\begin{array}{c}4.4 \\
(4.1-4.8)\end{array}$ & $\begin{array}{c}5.1 \\
(4.7-5.5)\end{array}$ & $0.68^{c}$ & -0.20 & .33 \\
\hline $\begin{array}{l}\text { Hemoglobin } \\
A_{1 c} \text { tests }\end{array}$ & $\begin{array}{c}2.0 \\
(1.8-2.1)\end{array}$ & $\begin{array}{c}2.4 \\
(2.2-2.5)\end{array}$ & $0.41^{c}$ & $\begin{array}{c}2.0 \\
(1.8-2.2)\end{array}$ & $\begin{array}{c}2.3 \\
(2.2-2.5)\end{array}$ & $0.31^{c}$ & 0.11 & .09 \\
\hline LDL tests & $\begin{array}{c}1.4 \\
(1.2-1.5)\end{array}$ & $\begin{array}{c}1.5 \\
(1.4-1.7)\end{array}$ & $0.17^{d}$ & $\begin{array}{c}1.4 \\
(1.3-1.6)\end{array}$ & $\begin{array}{c}1.5 \\
(1.4-1.6)\end{array}$ & 0.08 & 0.09 & .09 \\
\hline \multicolumn{9}{|c|}{ Hemoglobin $A_{1 c}=$ glycated hemoglobin; $C l=$ confidence interval; $L D L=$ low-density lipoprotein. } \\
\hline \multicolumn{9}{|c|}{$\begin{array}{l}\text { a The intervention effect column illustrates the differential amount of change in the intervention arm relative to the control arm comparing pre- with postintervention. } \\
\text { b } P \text { value associated with the time } \times \text { condition term in a generalized linear mixed model with repeated time measurements, study arm, and their interaction. } \\
\text { c } P<.001 \text {. } \\
\text { d } P<.01 \text {. } \\
\text { e } P<.05 \text {. }\end{array}$} \\
\hline
\end{tabular}




\section{Table 3. Changes and Proportion of Adult Diabetes Patients at Goal on Glycated Hemoglobin, Blood Pressure, and LDL Cholesterol Measures Among Intervention and Control Group Primary Care Physicians and Clinics in the Preintervention (Baseline) and Postintervention Periods}

\begin{tabular}{|c|c|c|c|c|c|c|c|c|c|}
\hline \multirow[b]{2}{*}{ Variable } & \multirow[b]{2}{*}{ No. } & \multicolumn{3}{|c|}{ Intervention Clinic } & \multicolumn{3}{|c|}{ Control Clinic } & \multirow[b]{2}{*}{$\begin{array}{c}\text { Intervention } \\
\text { Effect }^{\mathrm{a}}\end{array}$} & \multirow[b]{2}{*}{$\begin{array}{c}P \\
\text { Value }^{b}\end{array}$} \\
\hline & & Baseline & $\begin{array}{c}\text { Post- } \\
\text { intervention }\end{array}$ & Change & Baseline & $\begin{array}{c}\text { Post- } \\
\text { intervention }\end{array}$ & Change & & \\
\hline $\begin{array}{c}\text { Hemoglobin } A_{1 c,} \\
\text { mean }(S E), \%\end{array}$ & 1,092 & $\begin{array}{l}8.5 \\
(0.09)\end{array}$ & $7.9(0.09)$ & $-0.58^{c}$ & $\begin{array}{l}8.4 \\
(0.08)\end{array}$ & $8.1(0.08)$ & $-0.32 c$ & -0.26 & .01 \\
\hline $\begin{array}{l}\text { Hemoglobin } \mathrm{A}_{1 \mathrm{c}} \\
\quad<7 \%, \%(\mathrm{SE})\end{array}$ & 1,144 & & $78.4(2.0)$ & & & $79.2(2.0)$ & & -0.8 & .80 \\
\hline $\begin{array}{l}\text { SBP, mean (SE), } \\
\text { mm Hg }\end{array}$ & 894 & $\begin{array}{l}141.3 \\
(0.70)\end{array}$ & $130.5(0.70)$ & $-10.8^{c}$ & $\begin{array}{l}141.6 \\
(0.69)\end{array}$ & $131.5(0.69)$ & $-10.1^{c}$ & -0.70 & .56 \\
\hline $\begin{array}{l}\text { SBP }<130 \mathrm{~mm} \mathrm{Hg} \\
\%(\mathrm{SE})\end{array}$ & 1,506 & & $80.2(1.6)$ & & & $75.1(1.6)$ & & 5.1 & .03 \\
\hline $\begin{array}{l}\text { DBP, mean (SE), } \\
\text { mm Hg }\end{array}$ & 731 & $\begin{array}{l}85.1 \\
(0.52)\end{array}$ & $76.8(0.52)$ & $-8.3^{c}$ & $\begin{array}{l}84.6 \\
(0.51)\end{array}$ & $77.1(0.51)$ & $-7.5^{c}$ & -0.82 & .38 \\
\hline $\begin{array}{l}\text { DBP }<80 \mathrm{~mm} \mathrm{Hg} \\
\% \text { (SE) }\end{array}$ & 1,669 & & $85.6(1.4)$ & & & $81.7(1.5)$ & & 3.9 & .07 \\
\hline $\begin{array}{l}\text { LDL cholesterol, } \\
\text { mean (SE), mg/dL }\end{array}$ & 868 & $\begin{array}{c}122.3 \\
(1.7)\end{array}$ & $97.9(1.8)$ & $-24.4^{c}$ & $\begin{array}{r}124.1 \\
(1.7)\end{array}$ & $98.3(1.8)$ & $-25.8^{c}$ & 1.37 & .62 \\
\hline $\begin{array}{l}\text { LDL cholesterol } \\
<100 \mathrm{mg} / \mathrm{dL} \text { (or } \\
<70 \mathrm{mg} / \mathrm{dL} \text { if heart } \\
\text { disease), } \% \text { (SE) }\end{array}$ & 1,362 & & $85.2(1.6)$ & & & $83.9(1.5)$ & & 1.4 & .53 \\
\hline \multicolumn{10}{|c|}{$\begin{array}{l}\text { a The intervention effect column illustrates the differential amount of change in the intervention arm relative to the control arm comparing before and after the } \\
\text { intervention. } \\
{ }^{b} \text { For mean value analysis, } P \text { value associated with the time } \times \text { condition term in a general linear mixed model with repeated time measurements, study arm, and } \\
\text { their interaction. For proportion at goal analysis, } P \text { value associated with study arm. } \\
{ }^{c} P<.001 \text {. }\end{array}$} \\
\hline
\end{tabular}

\section{Figure 3. Diabetes Wizard use during and after intervention for the intervention group only.}

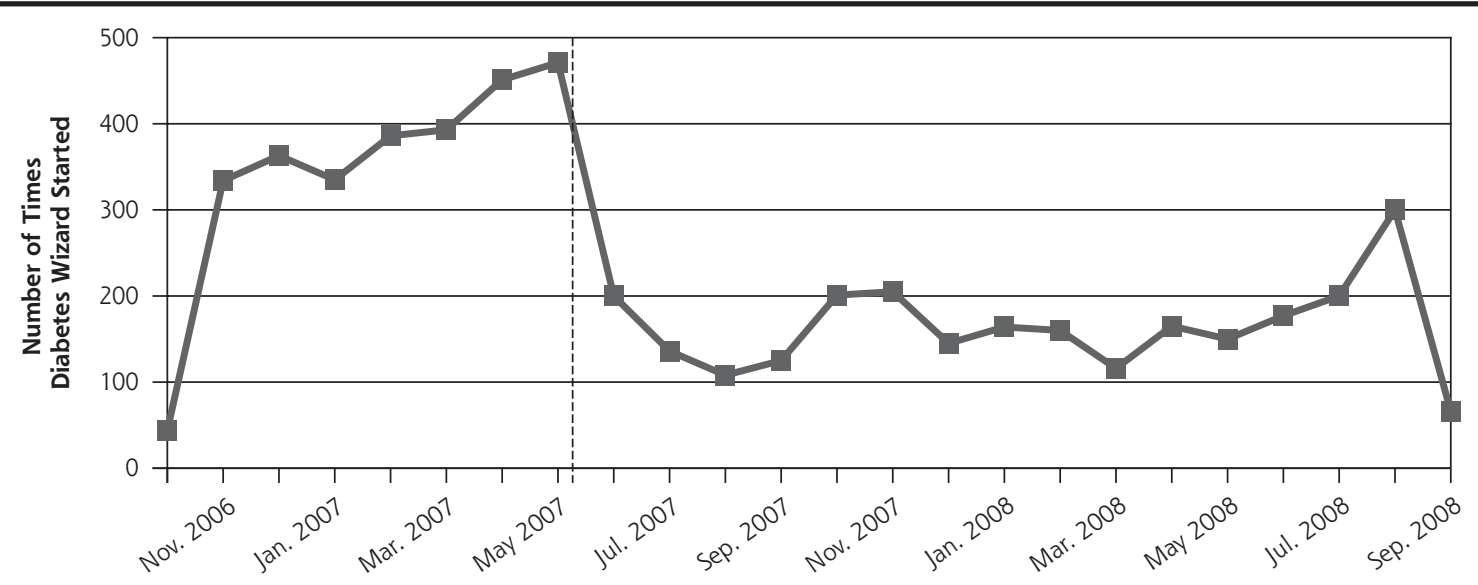

Note: Frequency of Diabetes Wizard use per month in intervention clinics shown on the vertical axis. Incentives and feedback on use of the Diabetes Wizard were provided from November 2006 to mid-May 2007. Sustained use of the Diabetes Wizard clinical decision support tool was observed at a lower rate after incentives and feedback stopped.

baseline were more likely to remain in control than control arm patients $(80.2 \%$ vs $75.1 \%, P=.03)$. The intervention had no significant positive or negative impact on diastolic blood pressure and LDL cholesterol values or proportion remaining in control for hemoglobin $A_{1 c}$, diastolic blood pressure, or LDL cholesterol values. Intervention benefits on hemoglobin $A_{1 c}$ levels occurred in both sexes and in both white and nonwhite patients.
During the 6-month period when use of the EHRbased clinical decision support system was reinforced by financial incentives and feedback, the Diabetes Wizard was opened at $62.6 \%$ of all visits made by diabetes patients to intervention physicians. After discontinuation of incentives and feedback, use of the Diabetes Wizard at the intervention clinics persisted at a lower level for 12 more months (Figure 3). Control 
group clinics did not have access to the intervention during the 18-month study. In a postintervention survey of 20 intervention group physicians, 17 of 18 respondents reported being completely satisfied or satisfied with this decision support system.

During the 6-month intervention period, physicians were asked to complete the Visit Resolution Form at the conclusion of each visit at which the Diabetes Wizard was used. Physicians reported intensifying glucose treatment in 536 of 866 (61.9\%) visits when the hemoglobin $A_{1 c}$ level was $>7 \%$. Blood pressure treatment was intensified at 363 of 832 visits (43.6\%) when blood pressure was $>130 / 80 \mathrm{~mm} \mathrm{Hg}$ at that visit; note that Diabetes Wizard deployed whenever the current blood pressure was $\geq 130 / 80 \mathrm{~mm} \mathrm{Hg}$, even if the patient's blood pressure was within target range at the prior visit. Rates of lipid treatment intensification were lower at 310 of 1,652 visits (18.8\%) when lipids were not at goal. Analysis of EHR data on newly prescribed drugs, however, did not show significantly different rates for those with a hemoglobin $A_{1 \mathrm{c}}$ level of $\geq 7 \%(10.7 \%$ vs $10.5 \%, P=.86)$ or blood pressure of $\geq 130 / 80 \mathrm{~mm} \mathrm{Hg}(13.9 \%$ vs. $14.0 \%, P=.98)$, although new lipid drugs were prescribed more often in the intervention group for those with a LDL cholesterol value of $\geq 100 \mathrm{mg} / \mathrm{dL}(9.1 \%$ vs $5.6 \%, P=.001)$. These data, taken together, suggest that many of the treatment intensifications reported by intervention group physicians were related to drug dose titrations (rather than newly prescribed drugs), or to lifestyle advice or interventions.

\section{DISCUSSION}

These data show that an EHR-based clinical decision support system led to modest but significant improvements in glucose control and some aspects of blood pressure control. Primary care physicians reported high levels of satisfaction with the intervention and had high rates of use of the clinical decision support system during the intervention period and continued to use the technology for more a year after incentives and feedback were discontinued, although at a lower rate. Patients of intervention physicians who were and were not exposed directly to the clinical decision support system had comparable improvement in hemoglobin $\mathrm{A}_{1 \mathrm{c}}$ levels and systolic blood pressure during the follow-up period. This finding suggests that physicians were able to transfer what they learned from using the clinical decision support system with some patients to the care of other patients - an important challenge and desirable finding in learning research.

This clinical decision support system used a strategy of personalization. As Figure 2 shows, clinical decision support went beyond prompts and reminders to include drug-specific treatment suggestions based on each patient's current treatment; distance from clinical goal, comorbidities, and renal and hepatic function. This type of clinical decision support system simultaneously standardizes and personalizes diabetes care. As personalization of chronic disease care increases in the coming era of genomic medicine, EHR-embedded clinical decision support may become an essential tool needed to systematically process complex risk prediction data and then accurately identify appropriate clinical goals and high-priority treatment options for each patient at each clinical encounter. ${ }^{36,37}$

In this study, the use of EHR-based clinical decision support technology was reinforced by changes in clinic rooming procedures, changes in nurse roles, and provision of incentives to physicians and clinic staffelements that were lacking in previous failed attempts to implement EHR-based clinical decision support. Physicians were provided clinical decision support information immediately before the start of the visit to facilitate visit planning. ${ }^{8,38}$ Although this intervention was well-received by physicians, it is uncertain whether high levels of use and satisfaction can be replicated when financial compensation is replaced by other incentives, such as pay-for-performance programs or public reporting of chronic disease quality of care. ${ }^{39}$

The study was conducted in a medical group with relatively good baseline diabetes care, and the magnitude of clinical improvement was quite modest. Even so, these modest results provide proof of concept that (1) under certain circumstance primary care physicians will use sophisticated point-of-care clinical decision support systems, and (2) when such clinical decision support systems are used, they can improve several intermediate outcomes of chronic disease care. Further efforts to strengthen the impact of clinical decision support on chronic disease care are justified and are already underway. Such efforts include prioritizing care recommendations based on benefit to the patient, enhancing the clinical decision support interface with physicians, and developing engaging and informative interfaces with patients that elicit and integrate patient preferences for care. ${ }^{40}$

Interpretation of our results is limited by several factors. First, the study site had relatively good baseline levels of diabetes care. The impact of clinical decision support in other practice settings may be greater or less than what we observed. Second, studies that explore alternative and less-expensive incentive strategies are needed. ${ }^{41}$ Third, additional work is needed to elucidate more precisely the specific mechanisms that were responsible for the observed effects of this intervention 
Despite these limitations, our data provide proofof-concept that an EHR-based clinical decision support system can improve key intermediate outcomes of diabetes care in primary care settings. The observed clinical impact, although modest, is comparable to that achieved by many disease management or patient education programs that are more expensive. ${ }^{42-46}$ EHRbased clinical decision support is scalable and can be used in conjunction with additional care improvement strategies. In the coming era of personalized medicine, clinical decision support strategies capable of simultaneously standardizing and personalizing clinical care will likely become an essential tool in primary care, and investments to further enhance the effectiveness of this technology are urgently needed.

To read or post commentaries in response to this article, see it online at http://www.annfammed.org/cgi/content/full/9/1/12.

Key words: Electronic health records; diabetes mellitus; quality of health care; quality improvement; glucose control; blood pressure control; primary health care; randomized trial

Submitted March 29, 2010; submitted, revised, August 23, 2010; accepted August 27, 2010

Funding support: This project was funded by National Institute of Diabetes, Digestive, and Kidney Diseases (NIDDK) grant \# R01 DK068314 to HealthPartners Research Foundation.

Trial Registration: clinicaltrials.gov NCT00272402.

\section{References}

1. Hoerger TJ, Segel JE, Gregg EW, Saaddine JB. Is glycemic control improving in U.S. adults? Diabetes Care. 2008;31(1):81-86.

2. Saydah SH, Fradkin J, Cowie CC. Poor control of risk factors for vascular disease among adults with previously diagnosed diabetes. JAMA. 2004;291(3):335-342.

3. Parchman ML, Pugh JA, Romero RL, Bowers KW. Competing demands or clinical inertia: the case of elevated glycosylated hemoglobin. Ann Fam Med. 2007;5(3):196-201.

4. Karter AJ, Parker MM, Moffet HH, Ahmed AT, Schmittdiel JA, Selby JV. New prescription medication gaps: a comprehensive measure of adherence to new prescriptions. Health Serv Res. 2009;44(5 Pt 1): 1640-1661

5. Bolen SD, Bricker E, Samuels TA, et al. Factors associated with intensification of oral diabetes medications in primary care provider-patient dyads: a cohort study. Diabetes Care. 2009;32(1):25-31

6. McEwen LN, Bilik D, Johnson SL, et al. Predictors and impact of intensification of antihyperglycemic therapy in type 2 diabetes: translating research into action for diabetes (TRIAD). Diabetes Care. 2009;32(6):971-976.

7. Von Korff M, Gruman J, Schaefer J, Curry SJ, Wagner EH. Collaborative management of chronic illness. Ann Intern Med. 1997;127(12): 1097-1102.

8. Wagner EH. Chronic disease management: what will it take to improve care for chronic illness? Eff Clin Pract. 1998;1(1):2-4.

9. De Jaegher $K$, Jegers $M$. The physician-patient relationship as a game of strategic information transmission. Health Econ. 2001;10(7): 651-668.
10. Montori VM, Dinneen SF, Gorman CA, et al.; Translation Project Investigator Group. The impact of planned care and a diabetes electronic management system on community-based diabetes care: the Mayo Health System Diabetes Translation Project. Diabetes Care. 2002;25(11):1952-1957.

11. Meigs JB, Cagliero E, Dubey A, et al. A controlled trial of webbased diabetes disease management: the MGH diabetes primary care improvement project. Diabetes Care. 2003;26(3):750-757.

12. Ziemer DC, Doyle JP, Barnes CS, et al. An intervention to overcome clinical inertia and improve diabetes mellitus control in a primary care setting: improving primary care of african americans with diabetes (IPCAAD) 8. Arch Intern Med. 2006;166(5):507-513.

13. Peterson KA, Radosevich DM, O'Connor PJ, et al. Improving diabetes in practice: findings from the TRANSLATE trial. Diabetes Care. 2008:dc08-2034.

14. Grant RW, Wald JS, Schnipper JL, et al. Practice-linked online personal health records for type 2 diabetes mellitus: a randomized controlled trial. Arch Intern Med. 2008;168(16):1776-1782.

15. Crosson JC, Stroebel C, Scott JG, Stello B, Crabtree BF. Implementing an electronic medical record in a family medicine practice: communication, decision making, and conflict. Ann Fam Med. 2005; 3(4):307-311.

16. O'Connor PJ, Crain AL, Rush WA, Sperl-Hillen JM, Gutenkauf JJ, Duncan JE. Impact of an electronic medical record on diabetes quality of care. Ann Fam Med. 2005;3(4):300-306

17. Gaede $\mathrm{P}$, Lund-Andersen $\mathrm{H}$, Parving $\mathrm{HH}$, Pedersen O. Effect of a multifactorial intervention on mortality in type 2 diabetes. $N$ Engl J Med. 2008;358(6):580-591.

18. Holman RR, Paul SK, Bethel MA, Matthews DR, Neil HA. 10-year follow-up of intensive glucose control in type 2 diabetes. $N$ Engl J Med. 2008;359(15):1577-1589.

19. Patel A, MacMahon S, Chalmers J, et al.; ADVANCE Collaborative Group. Effects of a fixed combination of perindopril and indapamide on macrovascular and microvascular outcomes in patients with type 2 diabetes mellitus (the ADVANCE trial): a randomised controlled trial. Lancet. 2007;370(9590):829-840.

20. Gerstein HC, Miller ME, Byington RP, et al.; Action to Control Cardiovascular Risk in Diabetes Study Group. Effects of intensive glucose lowering in type 2 diabetes. N Engl J Med. 2008;358(24):2545-2559.

21. Dluhy RG, McMahon GT. Intensive glycemic control in the ACCORD and ADVANCE trials. N Engl J Med. 2008;358(24):2630-2633.

22. Tierney WM, Overhage JM, Murray MD, et al. Effects of computerized guidelines for managing heart disease in primary care. J Gen Intern Med. 2003;18(12):967-976.

23. Montgomery AA, Fahey T. A systematic review of the use of computers in the management of hypertension. J Epidemiol Community Health. 1998;52(8):520-525

24. Murray MD, Harris LE, Overhage JM, et al. Failure of computerized treatment suggestions to improve health outcomes of outpatients with uncomplicated hypertension: results of a randomized controlled trial. Pharmacotherapy. 2004;24(3):324-337.

25. Balas EA, Krishna S, Kretschmer RA, Cheek TR, Lobach DF, Boren SA. Computerized knowledge management in diabetes care. Med Care. 2004;42(6):610-621.

26. O'Connor PJ, Rush WA, Pronk NP, Cherney LM. Identifying diabetes mellitus or heart disease among health maintenance organization members: sensitivity, specificity, predictive value, and cost of survey and database methods. Am J Manag Care. 1998;4(3):335-342.

27. Brown AF, Mangione CM, Saliba D, Sarkisian CA. Guidelines for improving the care of the older person with diabetes mellitus. J Am Geriatr Soc. 2003;51(5 Suppl Guidelines):S265-S280.

28. Charlson ME, Pompei P, Ales KL, MacKenzie CR. A new method of classifying prognostic comorbidity in longitudinal studies: development and validation. J Chronic Dis. 1987;40(5):373-383. 
29. Kieszak SM, Flanders WD, Kosinski AS, Shipp CC, Karp H. A comparison of the Charlson comorbidity index derived from medical record data and administrative billing data. J Clin Epidemiol. 1999;52(2):137-142.

30. Intitute for Clnical Systems Improvement (ICSI). Diagnosis and Management of Type 2 Diabetes Mellitus in Adults. Bloomington, MN, Institute for Clinical Systems Improvement; 2009.

31. Treatment of Type 2 Diabetes. Online Point of Care clinical decision support tool marketed as part of BMJ Point of Care. Concise and practical information on etiology, epidemiology, and clinical management of type 2 diabetes. 2010. https://online.epocrates .com/u/291124/Type+2+diabetes+mellitus. Accessed Aug 31, 2008

32. Huisman TH, Henson JB, Wilson JB. A new high-performance liquid chromatographic procedure to quantitate hemoglobin $A_{1 c}$ and other minor hemoglobins in blood of normal, diabetic, and alcoholic individuals. J Lab Clin Med. 1983;102(2):163-173.

33. Friedewald WT, Levy RI, Fredrickson DS. Estimation of the concentration of low-density lipoprotein cholesterol in plasma, without use of the preparative ultracentrifuge. Clin Chem. 1972;18(6):499-502.

34. Solberg LI, Engebretson KI, Sperl-Hillen JM, Hroscikoski MC, O'Connor PJ. Are claims data accurate enough to identify patients for performance measures or quality improvement? The case of diabetes, heart disease, and depression. Am J Med Qual. 2006;21(4):238-245.

35. Murray DM. Design and Analysis of Group Randomized Trials. New York, NY: Oxford University Press; 1998.

36. Doria A WJ, Xu R, Gervino EV, et al. Interaction between poor glycemic control and 9p21 locus on risk of coronary artery disease in type 2 diabetes. JAMA. 2008;300(20):2389-2397.

37. Schelling JR AH, Nicholas SB, Pahl MV, et al.; The Family Investigation of Nephropathy and Diabetes Research Group. Genome-wide scan for estimated glomerular filtration rate in multi-ethnic diabetic populations: the family investigation of nephropathy and diabetes (FIND). Diabetes. 2008;57:235-243.
38. O'Connor PJ, Pronk NP. Integrating population health concepts, clinical guidelines, and ambulatory medical systems to improve diabetes care. J Ambul Care Manage. 1998;21(1):67-73.

39. Doran T, Fullwood C, Gravelle H, et al. Pay-for-performance pro grams in family practices in the United Kingdom. N Engl J Med. 2006;355(4):375-384

40. Heisler M, Vijan S, Anderson RM, Ubel PA, Bernstein SJ, Hofer TP. When do patients and their physicians agree on diabetes treatment goals and strategies, and what difference does it make? J Gen Intern Med. 2003;18(11):893-902.

41. Rodriguez HP, von Glahn T, Elliott MN, Rogers WH, Safran DG. The effect of performance-based financial incentives on improving patient care experiences: a statewide evaluation. J Gen Intern Med. 2009;24(12):1281-1288.

42. Norris SL, Glasglow RE, Engelgau MM, O'Connor PJ, McCulloch D. Chronic disease management: a definition and systematic approach to component interventions. Dis Manag Health Outcomes. 2003;11(8):477-488.

43. Norris SL, Nichols PJ, Caspersen CJ, et al. Increasing diabetes selfmanagement education in community settings. A systematic review. Am J Prev Med. 2002;22(4)(Suppl):39-66.

44. Norris SL, Nichols PJ, Caspersen CJ, et al. The effectiveness of disease and case management for people with diabetes. A systematic review. Am J Prev Med. 2002;22(4)(Suppl):15-38.

45. Norris SL, Lau J, Smith SJ, Schmid CH, Engelgau MM. Self-management education for adults with type 2 diabetes: a meta-analysis of the effect on glycemic control. Diabetes Care. 2002;25(7):1159-1171.

46. Schmittdiel JA, Uratsu CS, Fireman BH, Selby JV. The effectiveness of diabetes care management in managed care. Am J Manag Care. 2009;15(5):295-301. 